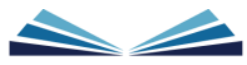

\title{
Genital Culture: Exploring the Cultural Importance of Genital Surgery in the West
}

\author{
Alexa Dodge \\ Carleton University, Department of Legal Studies
}

The assumed importance of genital surgery for intersex children as well as the rising popularity of cosmetic surgery for one's genitals (namely for women) exemplify the importance placed on gender distinction in Western culture. This paper will explore how these genital surgeries are tied to the idealized conception of the gender binary that exists in our culture. Despite the reality that genitals, especially the vulva, vary widely in appearance (size, shape, colour), the belief that there are norms of genital appearance that need to be adhered to continues to be propagated within Western culture. I will posit that genital surgeries in the West are a culturally imbued practice. This will be argued in light of Leti Volpp's assertion that people in the West need to recognize how our own culture promotes patriarchal/normative practices that can be dangerous and degrading to individuals. For instance, Western discourse vilifies cultures that engage in female genital mutilation (FGM) without realizing how Western culture itself pressures women to 'mutilate' their genitals through cosmetic surgery or intersex surgery. The cultural influence of the West must be acknowledged so that we can better perceive how the agency of Western subjects is also directed and confined by our cultural context. Western culture also acts upon its subjects and, in this case, pushes gender binaries and the ideal of the perfect 'normal' vagina. This paper will utilize queer theory to question the necessity of gender binaries and to reveal the way that binary gender is privileged in our society.

\section{Keywords: culture; genital surgery; gender binary; norms.}

L'importance majeure de la chirurgie génitale pour les enfants intersexués ainsi que la popularité croissante de la chirurgie esthétique pour les organes génitaux, particulièrement pour les femmes, illustrent l'importance accordée à la distinction entre les sexes dans la culture occidentale. Cet article examine comment ces interventions chirurgicales génitales sont liées à la conception idéale d'une sexualité binaire présente dans notre culture. En dépit du fait que les organes génitaux, particulièrement la vulve, varient largement en apparence en terme de taille, de forme ou de couleur, la croyance qu'il existe des normes d'apparence génitale qui doivent être respectées continue à être transmise dans la culture occidentale. Ce document soutient que les chirurgies génitales dans l'Ouest sont une pratique déterminée sociologiquement. Cet énoncé repose sur l'affirmation de Leti Volpp qui soutient que les Occidentaux doivent reconnaître comment leur propre culture favorise des pratiques patriarcales et normatives qui peuvent être dangereuses et dégradantes pour les individus. Par exemple, le discours occidental avilit les cultures qui pratiquent les mutilations génitales féminines (MGF) sans se rendre compte combien la culture occidentale elle-même exerce des pressions pour que les femmes « mutilent » leurs organes génitaux par la chirurgie esthétique ou par les opérations génitales intersexuelles. L'influence culturelle de l'Ouest doit être reconnue afin que nous puissions mieux comprendre comment le comportement des Occidentaux est également dicté et déterminé par son contexte culturel. La culture occidentale agit également sur ses sujets, et dans ce cas précis, favorise une sexualité binaire et l'idéal d'un vagin parfait et normalisé. Cet article s'appuie (texte supprimé) sur l'approche théorique homosexuelle pour remettre en question la nécessité d'une sexualité binaire, et pour révéler comment une sexualité binaire est privilégiée dans notre société

\section{Mots clés: culture; chirurgie génitale; sexualité binaire; normes.}


In "Feminism Versus Multiculturalism", Leti Volpp argues that Western conceptions of "thirdworld culture" as uniquely oppressive to women work to conceal the ways that Western society itself also promotes patriarchal and normative practices that can be dangerous and degrading to women (Volpp, 2001, p.1217). The argument in this paper will demonstrate how Western discourse vilifies cultures (namely those in varying countries throughout Africa and the Middle East) that engage in female genital mutilation (FGM) ${ }^{1}$ without realizing how the Western practices of intersex surgery and cosmetic vaginal surgery are also culturally imbued practices that can be seen as forms of genital mutilation. The assumed importance of genital surgery for intersex infants (Kessler, 2000, p.34) as well as the rising popularity of cosmetic surgery for women's genitals (Braun, 2009, p.133) exemplify the importance placed on gender distinction though genital appearance in our culture. Genital surgeries such as these are tied to the idealized conception of the gender binary that exists in Western culture. Despite the reality that genitals, especially the vulva, vary widely in appearance (size, shape, colour) (The Perfect Vagina, 2008), the belief that there are norms of genital appearance that need to be adhered to for females and males continues to be propagated within Western society. Suzanne Kessler's (2000) work on intersex surgeries and Virginia Braun's (2009) work on the growing popularity of cosmetic genital surgeries both illustrate how these norms are acted upon through genital surgery. The extreme surgical and emotional trauma that is taken on by individuals who undergo genital surgery is illustrative of the importance placed on normative ideals of gender through genital presentation. Although the enforcement of binary gender creates pervasive ideals that affect everyone in Western society (including constructing gendered norms for men and ideals of masculinity), this paper will focus on the way that Western society promotes glorified conceptions of vaginal appearance and the appearance of the female body in general. This focus will allow for a more in-depth examination of the similarities between Western genital surgeries and FGM by exposing how Western values also regulate the female body. For the purposes of this paper, the study of 'Western society' will focus most prominently on the United States, Canada, and the United Kingdom. This paper will utilize the theoretical framework of queer theory, specifically the work of Dean Spade, to reveal the way that binary gender is privileged in our society and how this privileging regulates Western subjects (Spade, 2004, p.241). The cultural influence of the West needs to be recognized so that we can better perceive how the agency of Western subjects is also directed and confined by our societal context. Western society is often conceived of as "normal" and "un-cultured" in comparison to the broad category of the "third-world", which is seen as abnormal and cultured (Volpp, 2001, p.1217). The use of Western society as the reference par excellence by which to measure other cultures arguably needs to be questioned (Mohanty, 1991, p.334). Western society is also a cultured space wherein subjects are regulated and controlled and, in this case, where the importance of gender norms and the idea of the perfect 'normal' vagina influence women and their bodies.

\section{Female Genital Mutilation and the Cultural Order}

Volpp (2001) exposes the way that Western discourses towards third-world and immigrant women act to construct an, overly broad, category of women as cultural 'others' that are deeply oppressed by their patriarchal culture, in contrast to Western women who are constructed as liberated actors living in a society that is free from patriarchy (Volpp, 2001, p.1198). Thereby, non-white and non-

${ }^{1}$ See Volpp 2001 for more on the vilification of cultural practices such as FGM. 
Western people are viewed as being 'ethnic', creating a cultural 'other' that is seen as distinct from, and abnormal in comparison to, the Westerner (Volpp, 2001, p.1190). These two categories of people are further polarized by the narratives of Western media that focus on third-world practices such as "...sati, dowry death, veiling, female genital surgeries, female infanticide, marriage by capture, purdah, polygamy, footbinding, and arranged marriages" to bolster conceptions of the oppression of the cultural other as "alien and bizarre..." (Volpp, 2001, p.1208). Martha Minow argues that Western narratives focus on practices such as these not only because we are intrigued by their bizarre and unfamiliar nature, but also because these practices are uncannily familiar to us: "...they illuminate 'otherness' but also, perhaps, echo something familiar, in reality or in metaphor, in the practices of the dominant Western nations" (Minow, 2000, p.128). In regard to FGM, this argument seems to ring true. Firstly, the cultural ideals of femininity and the desire to control female sexuality that motivate FGM are extremely familiar to Western society, as these ideals remain hugely influential to our culture. The significance of these ideals of the West will be discussed further in the section "Constructing women through genital and bodily appearance". Secondly, the specific 'mutilations' that fall under the heading of (FGM) are very similar to the surgical procedures that are performed in intersex and cosmetic vaginal surgeries. In fact, the very definition of FGM can be read to include both of these Western genital surgeries.

The World Health Organization (WHO) reports that practices of FGM are concentrated in 29 countries throughout Africa and the Middle East. Complications of FGM include severe bleeding, difficulty urinating, infections, and other medical complications. WHO defines FGM as including:

[All procedures that] alter or cause injury to the female genital organs for non-medical reasons. The procedure has no health benefits for girls and women. [FGM] comprises all procedures that involve partial or total removal of the external female genitalia, or other injury to the female genital organs for non-medical reasons (The World Health Organization, 2013).

A great deal has been written on the problematic nature of FGM and the human rights implications for the females that are forced to undergo this procedure. However, for the purposes of this paper, the Western gaze will be turned away from a focus on FGM and toward Western culture itself to reveal how similar issues are manifested in the West. Surgeries on intersex children adhere to the definition of FGM provided by WHO as they involve reducing in size, or removing entirely, parts of the female genitalia. The vast majority of these surgeries have no health benefits, and in fact often make the genitals less functional as they can result in extensive scarring, an inability for the individual to gain sexual pleasure, and/or extreme pain when sexually aroused (Kessler, 2000, p.45). Although some intersex surgeries are necessary for urination to occur without pain, most genital surgeries on intersex children are performed for the purely aesthetic reason of re-sculpting what are described in medical literature as genitals that are too "ambiguous" in appearance (Kessler, 2000, p.34). These surgeries can involve procedures such as clitoral reduction wherein the clitoris is seen as "too large", and thus "too phallic" in appearance (Kessler, 2000, p.37). These surgeries are similar to the category of FGM that WHO refers to as a clitoridectomy and describes as the "...partial or total removal of the clitoris" (The World Health Organization, 2013). Although the cultural reasons behind these two practices are different, both involve reducing in size or removing the clitoris and reflect cultural values about female sexuality that privilege the appearance and 
cultural meaning of female genitals over the functionality of these genitals and the ability for female sexual pleasure.

Further, two other types of FGM that WHO refers to as excision and infibulation, can be seen as similar to the cosmetic procedures that Western women are choosing to have performed on their vaginas. Excision, which is described as "the partial or total removal of the clitoris and the labia minora" (The World Health Organization, 2013), is comparable to what Western cosmetic surgeons refer to as labiaplasty. Labiaplasty involves "trimming" down the labia minora to "correct"/beautify labia that are seen as too large or asymmetrical (Manhattan Center for Vaginal Surgery, 2013). Again, this procedure is not performed for health reasons, but rather because the appearance of the labia minora could "cause embarrassment with a sexual partner or loss of selfesteem [or because] some women just want to look 'prettier' like the women they see in magazines or in films" (Manhattan Center for Vaginal Surgery, 2013). Similarly, infibulation, described as the "narrowing of the vaginal opening through the creation of a covering seal [that is] formed by cutting and repositioning the inner, or outer, labia, with or without removal of the clitoris" that is most often performed as a way to ensure women's virginity or sexual fidelity (The World Health Organization, 2013), is comparable to the Western cosmetic surgery referred to as vaginoplasty. Vaginoplasty is a surgical procedure that aims to "tighten the vagina" by "removing excess vaginal lining and tightening the surrounding soft tissues and muscles" (Manhattan Center for Vaginal Surgery, 2013). This surgery is often desired due to cultural pressures that tell women their vaginas should feel young, tight and virginal. The Manhattan Center for Vaginal Surgery's website explains the societal anxiety around the loose vagina when it warns that, following childbirth or due to ageing, a woman's "partner may notice a change although he may say nothing" (Manhattan Center for Vaginal Surgery, 2013). Again, although there are different cultural reasons around infibulation and vaginoplasty, and although cosmetic surgeries on adult women involve a greater amount of female choice and agency, both practices involve cultural pressures for female genitals to appear virginal and both involve women's bodies being altered for the purpose of male sexual pleasure. Therefore, the culturally imbued and possibly harmful nature of both intersex and cosmetic surgeries need to be exposed because, like FGM, they generally have no physical health benefits and involve subjecting individuals to painful surgeries that can result in the removal of, or damage to, previously functional genitals.

\section{Genital Culture in the West}

By focusing on how women are oppressed in "cultured" societies, Western society conceals the ways in which women, as well as intersex, trans, and gender non-conforming people, are oppressed by the West's binary gender enforcing culture. The enforcement of sex-gender alignment and the focus on genitals as a defining feature of one's identity in Western culture leads to the regulation of non-normative bodies and expressions of self. Despite the propagation of narratives of freedom and equality, Western society continues to be a highly patriarchal and heterosexist society that enforces gender binaries and the subordination of women as well as gender non-conforming subjects. In Herculine Barbin (1980), Michel Foucault discusses the modern Western idea that it is imperative for individuals to identify with one "true sex", that is with one gender that "matches" one's genitals (Foucault, 1980, p. vii). Foucault asks, "do we truly need a true sex?" and declares that, "with a persistence that borders on stubbornness, modern Western societies have answered in the affirmative" (Foucault, 1980:vii). Radical queer theorist Dean Spade is also concerned with the way that Western culture privileges binary gender and demands that individuals' gender identities 
"match" their biological sex based on genital appearance (Spade, 2004, p.243). Spade's (2004) theories have been influential in questioning deeply held Western gender norms and gendered practices that are often believed to be natural and acultural. The lens of queer theory seeks to undermine normative assertions that identities are static, natural and given, and is thus useful as a tool to contest the way that Western culture reinforces gender roles and normative gender enforcing practices. Spade asserts, "we all face the consequences of living in a capitalistic, binary genderenforcing context, where impossible standards of masculinity, femininity, and wealth keep us consistently punished and punishing for gender variation" (Spade, 2004, p.243). This enforcement of binary gender is exemplified by the fact that intersex children are assumed to need 'corrective' surgery despite the risks, pain, and side-effects that these surgeries involve and the fact that the 'ambiguity' of their genitals is of no consequence to their physical health. Therefore, these surgeries are not performed for the sake of health but due to the fact that intersex people "[call] into question the idea that female and male are biological givens compelling a culture of two genders" (Kessler, 2000, p.13). Surgeries are performed because the existence of intersex people questions the foundations of the binary gender enforcing and patriarchal society of the West. In Kessler's study of surgeons who perform intersex surgeries, she explains that these doctors do not feel a need to explain why these purely aesthetic surgeries are necessary to perform on intersex infants, aside from the simple explanation that if they are not performed these children will be teased about their genitals by other children later in life (Kessler, 2000, p.34). As Kessler explains, this teasing by other children is seen as reason enough to perform surgery. Due to the significance that is given to genital appearance and sex-gender "alignment" in Western culture, it is the genitals that are seen as wrong and in need of correction "rather than treating the teasing and the institutions that tolerate is as in need of correction" (Kessler, 2000, p.34). Members of the Intersex Society of North America (ISNA) are working to end genital surgeries on intersex infants (Kessler, 2000, p.80). ISNA hope to eliminate the shame around intersex genitals so that these children can live happy lives as intersex people, or at least make informed choices about surgery as adults rather than having the negative side effects of these surgeries forced upon them (Kessler, 2000, p.80). This is a difficult venture because, in a society that is as invested in binary gender as ours, the idea of leaving a child in a place in-between two genders can be interpreted as a form of psychological torture.

The growing popularity of elective vaginal surgeries is further proof of the idealized conceptions of gender and genitals that are privileged in Western society. The popularity of these surgeries has been steadily increasing since cosmetic genital surgery entered popular media in the late 1990's, and more surgeons than ever are offering these procedures (Braun, 2009, p.134). The "impossible standards" of femininity that Spade refers to in the quote above (Spade, 2004, p.243) are exemplified by cosmetic vaginal surgeries that are undergone due to cultural pressures to achieve what is perceived as 'normal', but is actually a socially constructed ideal of, vaginal appearance. Despite the reality that there is a wide spectrum of difference in the appearance of vaginas, for instance most labia minora range all the way from two to ten centimetres, women are led to believe that their vaginas are not 'normal' (The Perfect Vagina, 2008). Surgeons' websites promoting "designer vagina" surgeries utilize these societal ideals of femininity and vaginal appearance to attract potential clients (Braun, 2009, p.133). Thereby, these sites "work to pathologize genital diversity" by positing that it is not only physically abnormal but also psychologically harmful (Braun, 2009, p.137). The consequences of this pathologization are apparent in the fact that, in the last six years, a reported three hundred and forty-three cosmetic vaginal surgeries have been carried out on girls under the age of fourteen in the United Kingdom (Hope, 2012). These surgeries are justified by the belief that the anxieties these young girls harbour 
towards their genital appearance can result in low self-esteem that is psychologically damaging (Hope, 2012). The fact that cosmetic genital surgery is marketed as a necessary physical and psychological transformation (Braun, 2009, p.140) demonstrates the regulatory power that Western culture holds over both the bodies and minds of women in the West. It has been suggested that the pornography industry is to blame for the increasing anxiety around vaginal appearance, as this industry tends to display female performers with genitals that are small, symmetrical, waxed, and bleached (Manhattan Center for Vaginal Surgery, 2013). However, this is a very limited analysis of the situation, as there are a plethora of societal beliefs, institutions and industries that regulate female sexuality and influence the way women perceive their bodies.

\section{Constructing Women through Genital and Bodily Appearance}

FGM is perceived as a culturally significant practice that reflects the way women and femininity are conceived of in the cultures that practice it. As WHO asserts, "FGM is associated with cultural ideals of femininity and modesty, which include the notion that girls are 'clean' and 'beautiful' after removal of body parts that are considered 'male' or 'unclean"' (The World Health Organization, 2013). Although WHO makes this assertion with the intention of revealing the uniquely oppressed nature of women in these cultures, these same notions of women and femininity are clearly present in the Western practices of intersex surgery and cosmetic vaginal surgery. Both FGM and these Western genital surgeries are imbued with societal ideals of gender and femininity, and both expose the extent to which the cultures in which they are practiced act to control and regulate female bodies and female sexuality. Kessler describes how intersex surgeries are tied to gender ideals in regard to masculinity saying, "descriptions of the micropenis are tied quite explicitly to gender role" as males are seen as needing a large enough penis to "support masculinity" (Kessler, 2000, p.37-38). However, Kessler argues, "physicians do not question whether a large clitoris ill prepares a girl for the female role. The emphasis is more on its ugliness" (Kessler, 2000, p.37). I would argue that this focus on beautifying female genitals and on reducing genitals that are judged to be too large is in fact a significant indicator of the role that women are prescribed to play in Western culture. Women are taught that it is important for their bodies to be 'feminine', that is, attractive, small and unobtrusive. Sandra Lee Bartky reports that a study of typical feminine body posture by German photographer Marianne Wex revealed that women "make themselves small and narrow, harmless; they seem tense; they take up little space" (Bartkey, 1997, p.135). Bartky explains how these norms of femininity have become even more evident in the recent cultural trend towards extremely thin women in Western fashion magazines and media. She asserts, "massiveness, power, or abundance in a woman's body is met with distaste. The current body of fashion is taut, smallbreasted, narrow-hipped, and of a slimness bordering on emaciation" (Bartkey, 1997, p.132). These ideals of feminine appearance are reflected in both intersex and vaginal surgeries that aim to make female genitalia smaller and 'prettier'. For instance, labia minora reduction is the most popular cosmetic vaginal surgery due to women's anxiety around the possibility that their labia minora are too large or simply not pretty enough (Braun, 2009, p.137). Echoing cultural messages about ideas of the female bodily appearance, surgeons' sites such as that of the Manhattan Center for Vaginal Surgery say that the labia minora needs to be small, symmetrical, thin, and beautiful as well as to look "young" and "tight" (Manhattan Center for Vaginal Surgery, 2013). This site propagates and confirms female anxieties about labia minora that are "too large" by using page headings such as "Taut and Terrific" and "Neatness Counts" to assert that female genitals should be tidied up and hidden away to create a more 'feminine' appearance (Manhattan Center for Vaginal Surgery, 2013). 
Thus, female genitalia that are perceived to be too large are seen as not only aesthetically displeasing but also as culturally disturbing.

The regulation of, and disgust towards, larger female genitalia reflects the more general cultural ideals of the West that construct women as inferior to men and pressure women to remain unobtrusive, docile, and obedient (Bartky, 1997, p.143). Women's bodies are subjected to disciplinary practices, such as make-up and dieting, which are viewed as necessary for them to meet the cultural standards of beauty and size that are demanded of them (Bartky, 1997, p.139). Thus, women in our society can be made to feel ashamed when they do not live up to the diet, exercise, make-up, and hair removal regimes that are expected of them. As Bartky asserts, "a woman's face must be made up, that is to say, made over, and so must her body [...] but this presupposes that a woman's face, unpainted, is defective" (Bartky, 1997, p.139). The widely dispersed belief that female bodies are defective if they do not adhere to the ideals and normative standards ascribed by our society leads to a trend wherein women's bodies are judged and regulated by others as well as self-regulated by women themselves. Intersex and cosmetic vaginal surgeries are pertinent examples of the extent to which women's bodies are regulated to adhere to normative standards of feminine appearance. As mentioned above, the extent of the cultural significance of female genital appearance is revealed by the fact that the appearance of female genitals is often privileged over their functionality. For instance, in Kessler's studies, intersex surgeons asserted the belief that a surgically altered clitoris that is no longer able to attain sexual pleasure for a woman is preferable to a clitoris that can attain pleasure but is larger than average (Kessler, 2000, p.37). The significance placed on female genital appearance demonstrates Bartky's assertion that "to have a body felt to be 'feminine' - a body socially constructed through the appropriate practices - is in most cases crucial to a woman's sense of herself as female and, since persons currently can be only as male or female, to her sense of herself as an existing individual" (Bartky, 1997, p.146). With such huge significance being placed on the appearance of the female body, even what appears to be a Western woman's 'choice' to undergo elective vaginal surgery cannot be seen as an entirely free decision being carried out by a purely liberated woman. Rather, these surgeries could be perceived as a form of self-regulation that is influenced by cultural standards and constructed norms of femininity. Surgeons' websites, such as that of NewWoman Canada (NewWoman Canada, 2013), utilize the power of these culturally constructed standards by taking-up the language of normativity to convince women that their genitals may not be 'normal' and may require surgical intervention. Thereby, these sites engage in the regulatory pressure that leads to women's anxieties about their bodies' ability to live up to normative standards. For instance, NewWoman explains that labiaplasties are performed when "a woman wishes to correct the size and symmetry of her labia minora for normal sexual appearance" (emphasis added) (NewWoman Canada, 2013). What these websites do not explain is that this 'normal' sexual appearance is a constructed ideal created by our gender enforcing and patriarchal society, rather than an objective reality.

\section{Medical Rhetoric and Conceptions of Normality}

NewWoman, Manhattan Center for Vaginal Surgery and the medical literature studied by Kessler all use 'normal genitals' as the reference against which some genitals are judged to be abnormal and in need of surgical intervention. This constructed concept of genital normality is used alongside medical rhetoric to bolster the perception that Western genital surgeries are medical necessities that have only positive results. Conversely, non-Western forms of genital surgery are given the 
extremely value laden and horror-inducing name of female genital mutilation. Thus, despite the multiple similarities between these surgeries, one is presented as a benign medical procedure while the other is presented as a value-laden form of violence. That is, one is seen as genital mutilation and the other as genital normalization. Recognizing this double standard, the ISNA has attempted to use the cultural disgust towards FGM to argue for intersex rights: "in 1997 press releases, ISNA cleverly began to refer to intersex surgeries as 'IGM' to heighten the association with 'FGM"' (Kessler, 2000, p.80). Dean Spade has also acknowledged this double standard as he also refers to intersex surgeries as "intersex genital mutilation" (Spade, 2004, p.241). By echoing the language that is normally used to refer to non-Western or 'cultured' forms of genital surgery, these activists call into question the assumed legitimacy of intersex surgeries. This questioning helps to reveal that the use of medical rhetoric and the concept of normality act to elide the cultural and moral judgements at work in both intersex and cosmetic vaginal surgeries.

Elisabeth Lloyd's work on the use of conceptions of normality within the medical sphere is extremely helpful in understanding how Western society has come to view genitals that are 'ambiguous', 'too large', 'too small' or just 'ugly' as objectively wrong and in need of medical correction. Lloyd explains that it is commonly assumed that "science tells us what is normal or abnormal, diseased or healthy, and that the social and moral issues begin where the science leaves off" (Lloyd, 2008, p.133). In contrast to this assumption, Lloyd posits that "states of organisms do not announce themselves as desirable or undesirable, healthy or diseased, normal or abnormal; such classifications are inevitably applied by comparing the state of the organism to some ideal which serves a normative function" (Lloyd, 2008, p.134). Therefore, both health and normality are socially constructed categories that are based on cultural perceptions of "how we envision human life ought to be" (Lloyd, 2008, p.141). For instance, it is the culturally entrenched importance of binary gender that leads a doctor to define intersex genitals as abnormal and unhealthy. Although the result of this surgery may in reality be that the genitals have been damaged and are less functional, the surgeon views these genitals as having been 'corrected' and made 'normal' (Kessler, 2000 , p.40). Although cosmetic vaginal surgery may not be perceived as being as imperative as intersex surgeries, these surgeries are likewise influenced by societal norms and conceptions of what the ideal woman ought to look like.

\section{Issues of Agency and Concluding Comments}

In this paper I have engaged with Volpp's argument that a focus on immigrant and third-world women's oppression "diverts one's gaze from the sexism indigenous to [Western] culture and politics" (Volpp, 2001, p.1205). By comparing the "cultural' practice of FGM with the Western practices of intersex and cosmetic vaginal surgeries, I have hoped to demonstrate that Western women (and gender non-conforming people in the West) are also oppressed and regulated by their culture. I want to clarify here that I am not trying to argue that all women are simply victims of culture who are void of agency. Rather, I want to question the dichotomy that sets up third-world and immigrant women as purely oppressed and victimized, and Western women as "secular, liberated, and in total control of their lives" (Volpp, 2001, p.1198). The experiences of women in any culture cannot be simply defined as one of pure agency nor as one of pure victimization. Women in cultures that practice FGM are not totally void of agency, and women in the West who choose to undergo cosmetic vaginal surgery are not acting with pure agency that is free from societal pressures. This is not to deny the extreme emotional and physical trauma experienced by many women who undergo FGM procedures in countries throughout Africa and the Middle East, 
but rather to point out that we should not allow these extreme affronts to female agency to invisibilize the less obvert pressures that affect women in countries such as Canada, the United States, and England. WHO estimates that more than three million girls and women in African countries, namely in western, eastern, and north-eastern regions, are presently at risk of FGM. Additionally, many girls and women in some countries in Asia and the Middle East, and migrants from these areas living outside their home countries, are still at risk of undergoing FGM (The World Health Organization, 2013). Although it is important to recognize the injustice of FGM and the ways that this practice limits female agency, Western narratives around FGM need to deconstruct the false polarization between the West and the East to recognize the way that all people are influenced by the dominant norms of their culture.

The link between sex and truth posited by Foucault continues to be a hugely influential force in Western society (Foucault, 1980, p. x). The regulatory power of the cultural privileging of binary gender problematizes the perception of the West as a place defined by agency, choice and equality. In the case of cosmetic vaginal surgeries, it raises questions about "whether women can be said to choose cosmetic surgery, or whether that 'choice' is over determined by a larger patriarchal structure that makes cosmetic surgery seem like the only option for psychological survival in a world hostile to women's bodies" (Heyes \& Jones, 2009, p.7). While in the case of intersex surgeries on infants, the agency of these individuals is clearly jeopardized as these surgeries are carried out when the child is too young to provide consent. As Foucault attests, "biological theories of sexuality, juridical conceptions of the individual, forms of administrative control in modern nations, led little by little to rejecting the idea of a mixture of the two sexes in a single body, and consequently to limiting the free choice of indeterminate individuals" (Foucault, 1980 , p.x). Recognizing the regulatory power of this privileging of binary gender in Western culture, Spade calls for "[an] end [to] the mechanisms of coercion that incentivize binary gender" (Spade, 2004, p.241). Thus, both Foucault and Spade recognize the harm that results from the enforcement of ideals of binary gender. It is necessary to proliferate this recognition of the multiple ways that entrenched ideas of sex-gender alignment and the male-female gender binary influence Western society, as these concepts limit the choices available to individuals and lead to the punishment of those who do not conform to them. Until our society can recognize the way that the West influences and controls its people through binary gender, intersex children will continue to be subjected to unnecessary surgeries and some women will continue to choose cosmetic surgery in an attempt to attain the mythical 'normal' vagina.

\section{About the Author}

Alexa Dodge is a Masters student in the Legal Studies department at Carleton University. Her work focuses on gender theory. She can be reached at alexandra dodge@ carleton.ca

\section{References}

Bartky, S. L. (1997). Foucault, Femininity and the Modernization of Patriarchal Power. In Writing on the Body: Female Embodiment and Feminist Theory (pp. 129-154). New York: Columbia UP. 
Braun, V. (2009). Selling the 'Perfect' Vulva. In C. J. Heyes \& M. R. Jones (Eds.) Cosmetic Surgery: A Feminist Primer (pp. 133-152). Surrey: Ashgate Publishing Limited.

Foucault, M. (1980). Introduction. In Herculine Barbin: Being the Recently Discovered Memoires of a Nineteenth Century French Hermaphrodite (pp. vii-xvii). New York: Pantheon.

Heyes, C. J. \& Jones, M. (2009). Cosmetic Surgery in the Age of Gender. In Cosmetic Surgery: A Feminist Primer (pp. 1-20). Surrey: Ashgate Publishing Limited.

Hope, J. (2012, November 22). Hundreds of Girls Aged 14 or Under are Having 'Designer Vagina' Surgery on the NHS. Daily Mail, dailymail.co.uk.

Kessler, S. (2000). Lessons from the Intersexed. New Brunswick: Rutgers University Press.

Lloyd, E. A. (2008). Normality and Variation: The Human Genome Project and the Ideal Human Type. In Science, Evolution and Politics (pp. 133-147). Cambridge: Cambridge UP.

Manhattan Center for Vaginal Surgery (2013). Retrieved February 15, 2013, from www.manhattancenterforvaginalsurgery.com.

Minow, M. (2000). About Women, about Culture: About Them, about Us. Daedalus: The End of Tolerance: Engaging Cultural Differences, 129(4), 125-145.

Mohanty, C. (1991). Under western eyes: Feminist scholarship and colonial discourses. In Third World Women and the Politics of Feminism (pp. 333-358). Bloomington and Indianapolis: Indiana UP.

NewWoman Canada (2013). Vancouver Cosmetic, Reconstructive and Vaginal Surgery. Retrieved March 5, 2013, from www.newwoman.ca.

The Perfect Vagina (2008). Rogers, L. (Writer) \& Leach, H. (Director). UK: North One Television.

Spade, D \& Wahng, S. (2004). Transecting the Academy. GLQ: A Journal of Lesbian and Gay Studies, 10(2), 240-253.

Volpp, L. (2001). Feminism Versus Multiculturalism. Columbia Law Review, 101, 1181-1218.

The World Health Organization (2013). Female Genital Mutilation. Retrieved February 15, 2013, from www.who.int/mediacentre/factsheets/fs241/en/. 